Revista

\title{
Multi-Ensayos
}

Vol. $4, \mathrm{~N}^{\circ} 7$

ISSN: 2412-3285

https://multiensayos.unan.edu.ni

DOI: https://doi.org/10.5377/multiensayos.v4i7.9493

\section{Los cereales como fuente de alimentación primaria para la humanidad}

\section{Cereals as a primary food source for humanity}

\author{
Walter Lenín Espinoza Vanegas ${ }^{1}$
}

Recibido: 07 de marzo de 2018, Aceptado: 18 de octubre de 2018

\section{RESUMEN}

En el presente ensayo se abordan de forma sintetizada algunos aspectos relacionados con el hambre, la sequía y la importancia de la producción y consumo de cereales, una de las principales fuentes de alimentos para la población mundial, indistintamente de la posición social o económica que éstos ocupen.

Palabras claves: nutrición; cereales; prácticas estudiantiles.

\begin{abstract}
In this essay, some aspects related to hunger, drought and the importance of the production and consumption of cereals are summarized. Cereal is one of the main sources of food for the world population, regardless of the social or economic position they have.
\end{abstract}

Keywords: nutrition; cereals; students' internships.

1 Docente del Departamento de Ciencia, Tecnología y Salud, UNAN-Managua/FAREM-Estelí. Correo electrónico: walespinoza2003@ yahoo.com

Copyright (c) 2018 Revista Multi-Ensayos. 


\section{INTRODUCCIÓN}

La seguridad alimentaria representa una de las principales preocupaciones de nuestros tiempos. El crecimiento demográfico y las sequías provocadas por el cambio climático, se han convertido en razones primarias de la escasez alimentaria existente en el mundo entero.

En el presente documento, se abordan de forma sintetizada algunos aspectos relacionados con el hambre, fenómeno que está impactando negativamente a la humanidad, particularmente a aquellos con mayor vulnerabilidad por sus condiciones precarias en su calidad de vida. Este fenómeno se está convirtiendo en una causa de muerte de muchas personas, sobre todo en aquellos países donde el agua es escasa y la producción de alimentos casi es inexistente. Veremos que, ante situaciones críticas como el hambre, la producción de cereales se convierte en una fuente primaria de alimentos para humanidad, debido a sus características y propiedades nutritivas.

Se pretende reflexionar sobre cómo la agroindustria aporta de manera significativa a la producción y transformación de los cereales para el consumo humano, contribuyendo en gran medida a satisfacer las necesidades alimentarias de la población y coadyuvando a paliar la hambruna que se vive en los países considerados como los más empobrecidos del mundo.

\section{DESARROLLO}

\section{Pobreza y hambre en la historia de la humanidad}

La hambruna se define como la situación que se da cuando un país o una región geográfica no cuenta con los suficientes alimentos y recursos para satisfacer las necesidades de la población, por lo que se eleva la tasa de mortalidad debido al hambre y la desnutrición.

Las hambrunas han sido una constante en la historia de la humanidad. Este fenómeno se ha registrado a lo largo de los siglos en diferentes regiones del planeta, en distintas épocas y, desde luego, por motivos diferentes. Nunca, sin embargo, se había presentado una situación como la que vivimos en la actualidad, en que, según cifras de la ONU, mil millones de seres humanos padecen hambre.

Segú la Organización de las Naciones Unidas para la Alimentación y la Agricultura (2018), la situación se agrava y se vuelve más preocupante, si consideramos que - todavía de acuerdo con cifras del organismo internacional - alrededor de veinticuatro mil personas mueren diariamente por hambre o por causas relacionadas a la misma, y el setenta y cinco por ciento de los fallecidos son niños que no llegaron a los cinco meses de edad.

El problema de la pobreza y del hambre no puede tener soluciones simplistas. Se requiere de la participación de todos los países para buscar soluciones globales. Sin embargo, la mayor parte de los expertos en política alimentaria proponen, como punto de partida, disminuir en forma drástica la producción y el consumo global de carne, ya que parte importante de la producción mundial de granos se destina a la alimentación de los animales. 
La población mundial acaba de rebasar los siete mil millones de seres humanos, y su alimentación no puede estar subordinada a una dieta de carne. Los seres humanos tenemos que consumir otros alimentos, y la opción más viable son los vegetales, cuya producción debe incrementarse de manera importante, particularmente en lo que se refiere a los cereales.

\section{Los cereales como fuente de alimento}

El término cereal, de acuerdo a la Real Academia Española de la Lengua, es una planta gramínea cultivada principalmente por su grano, muy utilizado en la alimentación humana y animal, y de la que existen numerosas especies, como el trigo y la cebada. (Real Academia de la Lengua, 2018).

Según la mitología, el término "cereal” se deriva de Ceres, la diosa romana de la agricultura. Los cereales son un grupo de plantas dentro de otro más amplio: las gramíneas. La semilla y el fruto son prácticamente una y la misma cosa: los granos de los cereales, y los más utilizados en la alimentación humana son el maíz, el trigo y el arroz, pero también resultan importantes la avena, la cebada, el centeno y el mijo. Algunos cereales, como es el caso del trigo, la espelta y el centeno, contienen gluten, una proteína especial, que permite la elaboración de pan, y por eso se les llama cereales panificables. (Ramos Garmiño, 2013).

Entre éstos, los que más se producen y que más contribuyen a la alimentación de la humanidad son el maíz, originario de México, el trigo y el arroz. Por esta razón, se puede aseverar que maíz, trigo y arroz son los cereales que alimentan al mundo. Son éstos, en efecto, los que han venido a paliar las hambrunas sufridas por la humanidad a lo largo de la historia.

Nicaragua, es un país eminentemente agrícola y dentro de sus principales rubros de producción se encuentran cereales como el maíz y el arroz. Estos se consideran productos de primera necesidad, el primero porque admite muchos derivados de su semilla, convirtiéndolo en uno de los principales bastimentos para el acompañamiento de las comidas, además de la gran variedad de formas en que puede procesarse y consumirse; el segundo, porque forma parte de la dieta normal acompañado por los frijoles, otra fuente primaria de la dieta alimenticia nacional.

Se puede afirmar sin temor a la duda que en nuestros días los cereales tienen presencia en los cinco continentes, y su mayor o menor nivel de producción obedece tanto a las posibilidades que ofrece la agronomía, como a la demanda de la población. Sin embargo, no siempre fue así. La presencia de los cereales fue diferenciada en sus inicios, y los tres cereales principales en la alimentación humana: maíz, trigo y arroz, han caracterizado la evolución social y económica de los continentes del globo, y con ellos se les identifica.

Sobre este particular, Vega (2007) destaca que:

El arroz, el maíz y el trigo son indudablemente los tres cereales que más se cultivan en el mundo y los de mayor consumo humano. En los últimos años se ha estimado que el arroz ocupa aproximadamente 148 millones de hectáreas; el maíz, 140 millones, y el trigo, un poco más de 200 millones. Juntos proveen más del 60 por ciento de las calorías y proteínas necesarias en nuestra dieta diaria. 
En la misma línea, Serna (2007) se remonta a la antigüedad, y recuerda que

La agricultura comenzó hace unos 12 mil años, y desde entonces ha jugado un papel fundamental en el suministro de los alimentos y en el desarrollo de la humanidad. Desde ese entonces, los cereales han sido considerados la columna vertebral de la agricultura y el manantial más prolífico y abundante de alimentos.

Destaca, asimismo, su convicción de que el arroz, trigo y maíz continuarán siendo el sostén de la humanidad, principalmente en el mundo subdesarrollado. Los fitomejoradores y agrobiotecnólogos desarrollarán nuevas variedades e híbridos que mantengan su alta productividad en el campo, pero que contengan valores agregados, como un alto valor nutritivo y propiedades nutracéuticas o de beneficio probado en salud.

Aunque sus orígenes se remontan a la antigua Mesopotamia, el trigo es considerado el cereal de Europa y elemento primordial en la alimentación de los europeos; el maíz, con origen en México, es el cereal americano, y el arroz es el cereal asiático. De la misma forma, el sorgo, y su "pariente cercano", el mijo, son los considerados cereales africanos.

Según datos de la Organización de las Naciones Unidas para la Agricultura y la Alimentación, en todos los años de este incipiente milenio, la producción mundial de granos ha superado los dos mil millones de toneladas; de las cuales, mil doscientos millones de toneladas se logran por lo general en los países en desarrollo, en tanto que los países desarrollados no han logrado que su producción alcance los mil millones de toneladas. En cuanto a la producción por continentes, con base en el año 2008, las cifras de la FAO son las siguientes: Europa, 20.1\%; Asia, 42.9\%; América, 28.6\%; África, 6.6\%, y Oceanía, 1.9\%. Gracias a su contenido de almidón, de vitaminas, fibra dietética y azúcares de descomposición lenta, así como a su importante aportación de proteínas, carbohidratos y minerales, los cereales son la fuente más importante de nutrientes, y han constituido, por lo tanto, a lo largo de la historia, elemento fundamental para la alimentación de la humanidad.

Actualmente, el consumo de cereales es mayor que el de cualquier otro alimento. Se pueden consumir en su forma natural o procesados a partir de su transformación en harina. Se utilizan también como alimento para alimentación animal (ganado, cerdos, aves).

\section{Propiedades nutritivas de los cereales}

Según el INCAP (Instituto de Nutrición de Centro América y Panamá. INCAP/OPS, 2015), el mayor contenido de proteína lo tiene el trigo duro seguido del centeno y la avena. La cebada tiene el mayor contenido de fibra seguida de la avena. El maíz tiene el más alto contenido de grasa. En cuanto a minerales, la avena y la cebada tienen el mayor contenido de hierro y de calcio, mientras que el centeno y el trigo tienen el mayor contenido de fósforo. Finalmente, la avena y el trigo tienen el mayor contenido de tiamina.

Los alimentos elaborados a partir de cereales que conservan la cascarilla, se conocen como integrales; comúnmente se utiliza el trigo, el arroz y la avena. Los cereales integrales son una buena fuente de fibra, vitaminas y minerales, especialmente de folatos, vitamina $\mathrm{E}$ y selenio, que los han sido asociados con la disminución de los riesgos de padecer cáncer de colon. 
Algunos cereales aportan fibra soluble (como la avena) y otros insoluble (como la cascarilla del trigo). La fibra soluble ayuda a reducir el colesterol de la sangre y de allí que ayuda a reducir el riesgo de enfermedades del corazón. La fibra insoluble evita el estreñimiento.

Aún no se cuenta con evidencia suficiente para afirmar que la fibra en sí, se relaciona con la disminución del riesgo de padecer cáncer; sin embargo, es recomendable incluir cereales integrales en la dieta diaria por su aporte de otras

\section{Principales cereales producidos en la región}

A continuación, se menciona los volúmenes de producción de cereales, según datos proporcionados por la FAO, (Organización de las Naciones Unidas para la Alimentación y la Agricultura, 2018), y sus principales características, según el INCAP (Instituto de Nutrición de Centro América y Panamá. INCAP/OPS, 2015).

Maíz, es un cereal ampliamente difundido en el mundo, con una producción total anual de 817 millones de toneladas en 2009, la mayor entre todos los cereales. Es un alimento básico en muchos países y tiene múltiples aplicaciones como alimento animal y usos industriales. Su gran versatilidad genética le permite prosperar en climas tropicales, subtropicales y templados.

Características:

- Base de la alimentación de los pueblos centroamericanos.

- Planta adaptable y versátil por su diversidad de formas de preparación.

- Las variedades de mayor importancia como alimento humano son el maíz "duro" y el "dentado" de color amarillo o blanco.

- Proporciona principalmente energía a través de su contenido de carbohidratos.

- Es deficiente en los aminoácidos esenciales, lisina y triptófano, aunque se ha mejorado a través del desarrollo de variedades mejoradas como el maíz opaco-2 y nutricta.

- El valor nutritivo del maíz blanco, amarillo y negro es similar.

Arroz, es un alimento básico para más de la mitad de la población mundial y el segundo cultivo de cereales después del maíz, con una producción de 685 millones de toneladas en 2008 (FAOSTAT). Los mayores productores son China, India, Indonesia y Pakistán. El cultivo de arroz requiere de una mayor cantidad de agua que otros cereales y de más mano de obra.

Características:

- Principal fuente de energía en la dieta de millones de personas en todo el mundo.

- Contiene más almidón que cualquier otro cereal.

- Contiene pequeñas cantidades de tiamina, riboflavina y niacina que se encuentran en mayor cantidad en el arroz moreno que en el pulido.

- El arroz pulido se conserva por más tiempo debido a que se le ha eliminado el germen y con él la grasa que lo pone rancio.

- Los carbohidratos del arroz pulido se digieren fácilmente.

- Es de sabor suave que permite su consumo en grandes cantidades y frecuentemente sin producir hastío

- Es uno de los alimentos que no produce reacciones alérgicas. 
Trigo, se cultiva en todo el mundo bajo diversas condiciones climáticas. Ha sido el alimento básico de las principales civilizaciones de Europa, Asia y Norte de África durante más de 8000 años. En 2007 ocupó el tercer lugar entre los cereales más cultivados después del maíz y el arroz, con una producción mundial de más de 600 millones de toneladas (FAOSTAT). Como alimento básico utilizado en una gran variedad de productos, las operaciones de posproducción cumplen una función importante para crear un abastecimiento estable del producto. El trigo también se utiliza en la producción de alimentos animales, almidón y etanol.

Cebada, es el cuarto cultivo de cereales en términos de producción, con un total mundial de 136 millones de toneladas en 2007 (FAOSTAT). Requiere de un clima temperado para desarrollarse. Las principales áreas de cultivo se encuentran en Europa y en la Federación Rusa, aunque también es un cultivo valioso y resistente en las zonas áridas y semiáridas de Asia, Medio Oriente y el norte de África. Se utiliza fundamentalmente como harina para consumo humano, como alimento animal y como malta en la elaboración de bebidas alcohólicas.

Características:

- Su valor nutritivo se asemeja al de la avena y es superior al del arroz.

- Contiene más fibra que los otros cereales.

- Contiene más hierro que los otros cereales, a excepción de la avena.

Sorgo, es el quinto cultivo de cereales, con una producción mundial de más de 55 millones de toneladas en 2008 (FAOSTAT). La mayoría de las variedades son resistentes al calor y a la sequía, lo que lo convierte en un cultivo de gran relevancia en zonas desérticas. Es una importante fuente de alimento en África, Centroamérica y Asia meridional. Se le utiliza también en la producción de bebidas alcohólicas y biocombustibles.

Características:

- Sobrevive en condiciones de sequía mejor que otros cereales por lo que se cultiva en áreas donde la lluvia es escasa e impredecible. Sin embargo, las pérdidas son frecuentemente altas.

- Posee mayor cantidad y calidad de proteína que el maíz.

- Es rico en hierro y calcio.

Tomando en cuenta los nutrientes antes mencionados, la UNAN-Managua, a través de la Facultad Regional Multidisciplinaria de Estelí, ha fomentado las prácticas estudiantiles a través de la carrera de Ingeniería Agroindustrial, especialmente en el procesamiento de materias primas de la agroindustria alimenticia. Así pues, se ha realizado en el laboratorio de ingeniería agroindustrial un policereal con diferentes materias primas accesibles en el mercado local.

Este producto es innovador y con un costo asequible para la familia nicaragüense, particularmente la esteliana. Se elaboró con granos y frutos deshidratados, tales como: maní, el ajonjolí, piña, cebada, melón, avena, papaya, maíz y dulce de caña. Este producto aporta todos los nutrientes, proteínas, energía y micronutrientes que el cuerpo necesita, contribuyendo así a la seguridad alimentaria y nutricional. 


\section{CONCLUSIONES}

El incremento de la sequía, provocada por el cambio climático seguirá siendo una de las principales causas de hambruna a nivel global. Los países más vulnerables a los desastres naturales y los que se encuentran más expuestos a eventos de carácter bélico, seguirán siendo el blanco de catástrofes fatales como el hambre, provocando desnutrición y muerte e incrementando las tasas de mortalidad, principalmente la infantil.

El cultivo y producción de cereales representa una de las principales fuentes de alimentos para la población mundial, indistintamente de la posición social o económica que éstos ocupen. Por sus características nutritivas; por su costo relativamente moderado; por su capacidad para provocar pronta experiencia de saciedad; por su versatilidad y por la facilidad de su tratamiento agroindustrial o culinario, los cereales han sido, desde tiempo inmemorial, producto básico en la alimentación de los pueblos, y su consumo es adecuado para cualquier edad o condición.

Como parte de las prácticas estudiantiles, en la carrera de Ingeniería Agroindustrial, en la UNANManagua, FAREM-Estelí, se ha procesado un policereal de bajo costo y con los nutrientes necesarios para el organismo. Este es un aporte a la seguridad alimentaria y nutricional de la población estudiantil en particular, y de las familias estelianas en general.

\section{BIBLIOGRAFÍA}

Contenidos Actualizados en Nutrición y Alimentación - CADENA. (24 de 02 de 2018). Instituto de Nutrición de Centro América y Panamá - INCAP. Obtenido de Instituto de Nutrición de Centro América y Panamá - INCAP: http://www.incap.int/biblio/index.php/es/publi-a-la-venta/838contenidos-actualizados-en-alimentacion-y-nutricion-cadena

Instituto de Nutrición de Centro América y Panamá. INCAP/OPS. (2015). Cereales y sus productos. Módulo II. CADENA. GUatemala: INCAP.

Organización de las Naciones Unidas para la Alimentación y la Agricultura. (24 de 02 de 2018). Información sobre Operaciones de Pos Cosecha. Obtenido de Información sobre Operaciones de Pos Cosecha: http:/www.fao.org/in-action/inpho/crop-compendium/cereals-grains/es/?page=2\&ipp=7\&no_ cache=1\&tx_dynalist_pi1[par]=YToxOntzOjE6IkwiO3M6MToiMiI7fQ==

Real Academia de la Lengua. (24 de 02 de 2018). Obtenido de http://dle.rae.es/?id=8KRazcs. 